\title{
DESMONTANDO UN DISCURSO SECULAR. A PROPÓSITO DEL ÚLTIMO LIBRO DE SANTOS JULIÁ
}

\author{
JAIME COSGAYA GARCÍA \\ Universidad de Valladolid
}

\section{LA HISTORIOGRAFÍA, ANTE ESPAÑA Y SU REALIDAD HISTÓRICA}

No hace mucho, Stanley G. Payne advertía un incremento historiográfico de la problemática de la identidad española -y con ésta, a su vez, la de los nacionalismos periféricos-, a medida que las demandas de autodeterminación de ciertas regiones se han ido haciendo más intensas ${ }^{1}$. Sería preciso discutir los mecanismos que, según Payne, conectan tales demandas con el aumento de esa producción bibliográfica, en muchos casos polémica; y, sobre todo, la manera en que todo este fenómeno puede acabar finalmente impugnando el reconocimiento de la identidad histórica de nuestro país. Pero de cualquier modo, esa intuición resulta al menos válida para esbozar una primera sistematización de la bibliografía que el problema de España — por acogernos a la expresión más usual - ha generado². De acuerdo con esto, se podría hablar de dos amplios

1 Cfr. "Jesús Laínz y el problema de la "deconstrucción de España”, prólogo a LAínZ, J., "Adiós, España». Verdad y mentira de los nacionalismos, Encuentro, Madrid, 2004.

2 Cfr. ANDrés-GAllego, J., «El problema (y la posibilidad) de entender la historia de España», en ANDrÉs-Gallego, J. (coord.), Historia de la historiografía española, Encuentro, Madrid, 2003, pág. 330. Este autor utiliza esta expresión para valorar el lastre historiográfico que han supuesto ciertos tópicos a la hora de entender nuestro pasado, de los cuales hablaremos más adelante. Por ahora, baste señalar cómo a todos ellos se une la exigencia que plantea dar una respuesta satisfactoria a la pluralidad intrínseca española. Esta demanda ha venido a convertirse históricamente en una necesidad, constantemente reiterada además desde ciertos ámbitos territoriales, y cuestionada hoy día por una realidad social en vías de transformación ante hechos como la sucesiva llegada e inserción de inmigrantes.

Sin duda, todos estos aspectos están despertando el interés de los historiadores, que no rehúsan el reto de reinterpretar algunos de los conceptos políticos que han sustentado cualquier entramado constitucional en la edad contemporánea. Veáse, por ejemplo, la reciente aparición de la obra diri- 
campos temáticos: la idea de España, por un lado; y la de sus nacionalidades históricas, por otro. O lo que es lo mismo, la naturaleza o ser de España, y la revisión de la articulación político-administrativa de su territorio ${ }^{3}$.

Particularmente productivo se está revelando el primero de ellos. Tanto es así que recientemente ha deparado el Premio Nacional de Historia para la obra que aquí reseñamos. Dicho libro explica cómo en el recurso a la imagen simbólica de las dos Españas han encontrado justificación, en palabras de su autor, «las luchas ideológicas y políticas del siglo XIX y la entraña misma de la constitución de España en los primeros años del XX». De acuerdo con esto, las dos Españas no serían más que el relato interpretativo de la evolución política seguida por nuestro país durante los últimos doscientos años. En consecuencia, la dinámica inestable de este período tendría un reflejo inequívoco en el contenido de esta imagen: dos maneras de entender la situación española, excluyentes entre sí, y dispuestas a erigirse en la única alternativa posible al horizonte político propuesto por la modernidad ${ }^{4}$.

gida por José Álvarez Junco, junto a Justo G. BERAmENDI y Ferrán ReQueJo, El nombre de la cosa: debate sobre el término "nación" y otros conceptos, Centro de Estudios Políticos y Constitucionales, Madrid, 2005.

3 En relación con el segundo campo temático, que hemos desatendido por estar más centrada la obra de JuliÁ en la imagen de España en su conjunto, Pablo PÉREZ LóPEZ ha señalado cómo el renacer de la historia política tras el agotamiento de otros paradigmas interpretativos vino a asentarse sobre nuevas propuestas de análisis. La más destacada, por lo que a nuestra historiografía respecta, fue que «esa historia [política] no atendía tanto a la nación española, como en el siglo XIX, sino a las naciones españolas, a los conjuntos que —integrados en España - se autopercibían como nacionales» (cfr. prólogo a GonZÁlez Clavero, M., El proceso autonómico de Castilla y León. Los inicios (1975-1978), vol. I, Fundación Villalar, Valladolid, 2004, p. 11).

Sobre el surgimiento de los nacionalismos periféricos y su proyecto de articulación dentro del Estado liberal decimonónico, así como su planteamiento en el siglo XX y su encuadramiento en el actual orden político nacional e internacional, la revista $\operatorname{Ayer}(35,1999)$ cuenta con un amplio análisis coordinado por Anna Maria GARCíA RovirA que lleva por título «España, ¿nación de naciones?».

Finalmente, en los últimos años, la revisión histórica ha alcanzado también al actual Estado de las Autonomías, tanto desde el punto de vista jurídico-administrativo como fundamentalmente histórico. En este último sentido, una perspectiva general del tema la aportan la obra coordinada por Juan Pablo Fusi, España. Autonomías, Espasa Calpe, Madrid, 1989; y la realizada conjuntamente por José Luis DE la Granja, Justo G. BerAmendi y Pere ANGUERA, La España de los nacionalismos y las autonomías, Síntesis, Madrid, 2001; o de un modo más sintético, el resumen trazado por José Vidal-Pelaz LóPez en El Estado de las Autonomías. Regionalismos y Nacionalismos en la Historia Contemporánea de España, Actas, Madrid, 2001.

4 Las obras de Gonzalo REDONDO se han caracterizado por defender este esquema interpretativo, que se ajusta al análisis particular que hace de la cultura de la Modernidad. Este autor señala cómo el desarrollo de la contemporaneidad estuvo marcado por el derribo de los fundamentos del Antiguo Régimen. En este proceso de sustitución de unos principios políticos por otros, fue inevitable el enfrentamiento entre las fuerzas contrarias al cambio, y aquéllas partidarias del mismo. Veáse, por ejemplo, la aplicación de este esquema interpretativo al caso español en la introducción de Política, Cultura y Sociedad en la España de Franco (1939-1975). Tomo I. La configuración del Estado español, nacional y católico (1939-1947), EUNSA, págs. 9-26. 
Alimentada por escritores e intelectuales, la sugestión de esa doble imagen, polarizada y dialéctica, la hizo perdurar hasta el final del franquismo. Fue entonces cuando un nuevo relato basado en la idea de reconciliación revocó la secular división habida entre los españoles, acostumbrados a verse hasta ese momento - aun con los matices de cada caso- en los mismos términos siempre de «nosotros» y «ellos». A esas alturas, la historia de España había evidenciado ya las dificultades de articular un proyecto político que lograse arbitrar cierta alternancia en el poder sin ruptura alguna de por medios.

Juliá considera este discurso acerca de lo que fue nuestro pasado y de lo que debía ser nuestro futuro como una creación cultural. Por este motivo, en vez de hacer un elenco de las sucesivas interpretaciones que se fueron dando a la idea de España desde el siglo XIX, se centra en desmontar las diversas «tramas narrativas» en las que aquéllas se apoyaron. Estamos, por tanto, ante un obra que pone al descubierto la conexión existente a veces entre la reflexión histórica y la movilización política en cualquiera de sus formas.

De todo ello se deriva una mayor atención del autor al modo en que escritores e intelectuales insertaron su discurso dentro del imaginario colectivo de la sociedad, que a su estricto análisis crítico. Ese enfoque le permite extraer las claves de pasadas disputas culturales sin necesidad de entrar a valorar la retórica en juego; en ocasiones, excesivamente farragosa e ininteligible desde nuestra óptica. Se trata, en definitiva, de una perspectiva sugerente que aporta cierta novedad a los planteamientos que la historiografía reciente venía adoptando respecto a este tema.

A diferencia de los nacionalismos periféricos -a los que la bibliografía tiende a valorar antes como fenómeno político que como sujeto histórico con una personalidad específica-, la idea de España en la historiografía ha variado habitualmente entre la reflexión sobre su pasado y la que se ocupa de su identidad como nación. Desde el punto de vista del método y de la forma, cabría distinguir dos tipos de obras. Por un lado, los ensayos teóricos que han intentado definir España de acuerdo con los rasgos que históricamente la identifican como tal. Y por otro, aquellos ensayos de síntesis que han recopilado las interpretaciones que determinados hechos históricos, particularmente decisivos, han ido generando cada poco tiempo en función de nuevas fuentes o puntos de vista ${ }^{6}$.

5 Respecto a esa inestabilidad política de carácter casi endémico durante los dos últimos siglos, Enric UCELAY-DA CAL ha señalado que «en el imaginario hispánico, incluso en el inconsciente colectivo, la estabilidad perdurable de un sistema político siempre parece un deogracias, el descanso tras una experiencia dura, poco grata, traumática. La primera secuela contagiosa de tal desasosiego político es precisamente la desconfianza enfermiza, negación de cualquier "lealtad sistémica" imaginable: la postura ideológica considerada como intelectualmente moral -hasta superior- es la crítica destructiva frente al Poder supuestamente mal utilizado por los "otros"», (cfr. «Tristes tópicos: supervivencia discursiva en la continuidad de una "cultura de guerra civil" en España», en Ayer, 55, 2004, p. 92).

6 La historiografía reciente ha convertido en atípicas las clásicas disputas entre Américo CASTRO y Claudio SÁNCHEZ-ALBORNOZ a propósito del constitutivo esencial de la nación española. Así 
El libro de Juliá está más próximo a lo segundo. Aunque bien es cierto, como queda dicho, que no se propone narrar la evolución de la idea de España a lo largo de la contemporaneidad, sino la pervivencia de su imagen ambivalente y contradictoria. Por eso desde el punto de vista del lenguaje, se fija justamente en aquello que ha dado vigencia al argumento de las dos Españas, hasta incluso llegar a camuflarlo, en ocasiones, bajo la piel de interpretaciones contrarias ${ }^{7}$.

La metodología de Juliá sigue la misma línea de sus anteriores trabajos. Su interés hacia los postulados de la sociología histórica le ha llevado a ocuparse últimamente de los modos de presencia de los intelectuales en la esfera pública, clasificándoles en función no de su discurso sino del modo en que logran trans-

parece indicarlo su mayor querencia por la interpretación del pasado que por la definición de lo que es o ha sido históricamente España. Asimismo, es también significativo que tales interpretaciones que arrancan del debate histórico suscitado por hechos puntuales o por procesos de larga duración-, no se sustraigan de plantear la política que España debería haber adoptado ante tales circunstancias.

El resumen que Carlos DARDÉ MORALES hace de la idea de España en la historiografía del siglo XX profundiza en esta misma línea. Según este autor, la comprensión de España y su realidad histórica han estado condicionadas por su trayectoria política en estos últimos cien años. La secuencia de ideas que transita de la singularidad a la normalidad españolas vendría a ratificarlo: «un país único; un país marcado por el fracaso y, en ese sentido, diferente; y un país normal, aunque en crisis de identidad» (cfr. La idea de España en la historiografía del siglo XX, Universidad de Cantabria, Santander, 1999, p. 8). En relación al siglo XIX, un análisis de estas características puede verse en ÁLVAREZ JUNCO, J., Mater dolorosa. La idea de España en el siglo XIX, Taurus, Madrid, 2001.

Dos razones podrían explicar, a mi juicio, esta inclinación: la desacreditación de todo esencialismo histórico para referirse a la nación española, y la dificultad de analizar un «sujeto histórico» tan abstracto, por impersonal, como resulta España.

7 El breve ensayo de José ANDRÉS-GALLEGO, anteriormente citado, encierra cierto paralelismo en sus pretensiones con la obra de Santos Juliá. El libro de Juan Pablo Fusi, España: la evolución de la identidad nacional (Temas de Hoy, Madrid, 2000), también constituye una referencia en este sentido, aunque se detiene más en el proceso de formación de la idea de España que en su elaboración como discurso. El objetivo que Fusi se plantea no es otro que el de analizar cómo las distintas interpretaciones históricas sobre el devenir español han contribuido a «levantar», por así decir, la identidad nacional. Entendiendo siempre ésta última como un proceso "cuya marcha es siempre una evolución no lineal, discontinua, a menudo incoherente, $\mathrm{y}$, en cualquier caso, un proceso indeterminado, dinámico y abierto, esto es, que carece de punto de partida y de punto de llegada" (pág. 10). Este mismo enfoque, aunque referido exclusivamente a las aportaciones procedentes del ámbito historiográfico, también se observa en la obra coordinada por Ricardo GARCíA CÁRCEL, La construcción de las historias de España (Marcial Pons, Madrid, 2004), que pretende ser una síntesis del modo en que se ha elaborado la historia de España desde la época moderna. Asimismo, las implicaciones políticas que contiene todo discurso sobre la identidad nacional en España desde finales del siglo XIX hasta finales del XX se analizan ampliamente en la obra de Carolyn P. BOYD, Historia patria: política, historia e identidad nacional en España, 1875-1975, PomaresCorredor, Barcelona, 2000.

Por su parte, la Real Academia de la Historia ha salido al paso de las sospechas que merecen por lo general las definiciones esencialistas, tratando de dar un nuevo giro al modo de entender España. Dos ejemplos ilustrativos en este sentido, referidos a la entidad y nombre de este sujeto, pueden verse en España: reflexiones sobre el ser de España (Real Academia de la Historia, Madrid, 1998) y De Hispania a España: el nombre y el concepto a través de los siglos, (Temas de Hoy, Madrid, 2005), coordinada ésta última por Vicente PALACIO ATARD. 
mitirlo a la opinión general y el rol que consecuentemente terminan adoptando ante sus receptores. En este sentido, la introducción inicial es el armazón teórico de toda la obra, y representa el punto donde Juliá sitúa el estado de esta cuestión. Respecto a la temática, el autor dedica por vez primera a estos aspectos una obra de mayor amplitud que las colaboraciones que le sirvieron como primera aproximación, y que él mismo cita como preludio del presente libro ${ }^{8}$.

\section{LAS RAÍCES DE UNA DOBLE LÍNEA INTERPRETATIVA}

A partir de esta conceptualización del intelectual y de su intervención en la vida pública, Juliá aborda los tópicos que fueron cimentando la trama de las dos Españas hasta conseguir que la realidad se plegara a esta imagen ${ }^{9}$. No hubo reparo en que para ello, y sin distinción de credo político, hubiese que recurrir a «inventar la tradición» o a «adueñarse de la memoria».

Entre todos esos tópicos, especial atención mereció la extendida creencia de la singularidad histórica española, referida no tanto al carácter y personalidad de sus habitantes, como a su marcha política, ajena a la del resto de países occidentales. Ese complejo arraigó a medida que la crisis del Antiguo Régimen fue haciendo mella, y los síntomas de plenitud de siglos anteriores fueron apagándose en favor de otras potencias europeas emergentes.

Este descenso de protagonismo en el plano internacional hizo que los historiadores y los escritores e intelectuales se sintieran tentados de examinar las causas que habían conducido a esa situación. Al margen de coincidir o no en su identificación, unos y otros acabaron por enjuiciar todo el proceso, con la consiguiente atribución de responsabilidades. Se originó así una reflexión sobre el pasado que dejaba traslucir, por encima de cualquier otra, la sensación de decadencia ${ }^{10}$.

8 Cfr. Historias de las dos Españas, op. cit., p. 543. La producción bibliográfica de Santos Juliá ha estado especialmente centrada en la II República, a la que ha dedicado sus monografías más destacadas: La izquierda del PSOE, 1935-1936 (Siglo XXI, Madrid, 1977); Orígenes del Frente Popular en España 1935-1936 (Siglo XXI, Madrid, 1979); Madrid, 1931-1934: de la fiesta popular a la lucha de clases (Siglo XXI, Madrid, 1984); o Manuel Azaña, una biografía política: del Ateneo al Palacio Nacional (Alianza, Madrid, 1990). Una primera aproximación a las cuestiones que trata en su última obra, surgida a raíz del congreso en conmemoración del centenario del 98 que él mismo coordinó, puede verse en Debates en torno al 98: estado, sociedad y política, Consejería de Educación y Cultura, Madrid, 1998.

Por otro lado, su relación con la sociología histórica parte de haber sido el traductor al castellano de Perry ANDERSOn, en especial, de dos de sus obras más significativas: El Estado absolutista (Siglo XXI, Madrid, 1979), y Transiciones de la antigüedad al feudalismo (Siglo XXI, Madrid, 1979).

9 Un vistazo al índice del libro permite rastrear las diversas figuras de intelectual que presenta Juliá. Entre ellas, las del intelectual como «conciencia de la multitud», como «minoría selecta»o como «político de la cultura».

10 En un capítulo de su obra Un discours national? La Real Academia de la Historia entre science et politique (1847-1987), (Casa de Velázquez, Madrid, 2004), que lleva por título «L’Espagne, entre 
Ya se tratase de exculpar o culpar del retroceso a España, estaba claro que, en este punto del debate, habían quedado perfiladas dos líneas interpretativas que, partiendo del ocaso español, planteaban la manera de evitar los errores del pasado. Mientras una miraba al extranjero buscando imitar el modelo que remediase los males, la otra inspeccionaba en las entrañas de la tradición ansiando la recuperación de las viejas esencias ${ }^{11}$.

En estas dos líneas cabe agrupar a todos los escritores e intelectuales que desfilan por las páginas del libro. De los doceañistas encargados de avivar el papel del pueblo levantado en defensa de sus libertades, a los disidentes que cerraron la distinción entre vencedores y vencidos a finales de los años setenta del siglo pasado. En medio quedaron los que alumbraron el renacimiento de las otras naciones españolas y los que vieron en la aculturación de las masas el punto de apoyo sobre el que sustentar la recuperación moral, económica y política de España. A ser posible, encargándose ellos mismos de llevarla a cabo: desde la tribuna del periódico, desde el escaño parlamentario o haciendo prevalecer sus ideas en el campo de batalla. En todos sus discursos asistimos a una España capaz de ofrecer dos caras: la España liberal y la absolutista; la España del interior y la de la periferia; la España oficial y la real; la España vieja y la nueva; la España tradicional y la europea ${ }^{12}$.

No es ilógico pensar que la realidad histórica sea mucho más rica en matices que los fijados en este tipo de reducciones. Puede que por esa razón, Juliá prefiera no valorar en qué medida pudo contribuir a este gran relato la posible existencia de ejemplos análogos en países como Francia e Italia ${ }^{13}$. Por otro lado,

gloire et décadence», Benoît Pellistrand explica cómo la evocación de ideas como "gloria» y «decadencia» son realidades particularmente españolas.

11 José ANDRÉs-GALLEGO identifica ambas líneas con la visión liberal y con la tradicionalista: «Desde antes de que mediara el Ochocientos, se desenvolvió un haz de reflexiones que intentó dar razón del nuevo estado, de postración general, en que se veía al país. Reflexión que condujo -con una enorme variedad- a dos líneas interpretativas diversas: la que podemos denominar liberal y la que -recurriendo a una acepción estrictamente cultural, que puede interpretarse como equívoca por sus implicaciones políticas- denominaremos tradicionalista», op. cit., pág. 332.

Prosigue este autor diciendo que entre ambas no se produjo tanto una divergencia interpretativa como una diferencia de valoración que «tuvo consecuencias estrictamente historiográficas durante mucho tiempo, porque orientó las investigaciones en unos determinados sentidos y no en otros; pero que eso ocurrió porque sirvió principalmente para justificar una política (una política para el siglo XIX y sobre todo para el XX)», id., pág. 334.

12 Hay autores que han recurrido a esta dicotomía para narrar sus propias historias contemporáneas. Uno de los ejemplos más destacados, en este sentido, sea quizá el de José María GARCía EsCudero y su Historia politica de las dos Españas, Editora Nacional, Madrid, 1975. Aunque si se trata de enumerar, Vicente CACHO VIU llega a distinguir hasta tres en el juego político de la II República previo a la Guerra Civil; las representadas en las figuras de "los tres Franciscos": Francisco Giner de los Ríos, Francisco Largo Caballero y Francisco Franco, (cfr. Las tres Españas de la España contemporánea, Ateneo, Madrid, 1962, pág. 8).

13 «De two nations había hablado Disraeli en la novela Sybil -que conocía Joaquín Costa-, de "dos Francias" había escrito Renan en 1868; a dos Italias -una "legal” y otra "real" se había referido Stefano 
su completo manejo bibliográfico y de fuentes hemerográficas le sirve para contextualizar correctamente a cada uno de los escritores e intelectuales, aunque su narración tal vez se resienta en ese punto de su particular dedicación a Manuel Azaña.

Con todo, en mi opinión, el acierto de Juliá reside en llamar la atención sobre lo recurrentes que han sido esos tópicos. A mi juicio, ésa es la principal aportación de su obra, la de descubrir lo que esas visiones esconden o no dejan ver fácilmente. Hablar de «tramas narrativas» implica que, en el juego de discutir qué le había ocurrido a España y ver quién era el que finalmente acertaba, se emplearon argumentos de conveniencia. A la postre se vio cómo este debate, aparte de quedarse en pura retórica, sólo iba con una minoría preocupada de hacer discurrir el devenir político a la vera de sus propios intereses. La prueba para la posteridad quedó en períodos como la Segunda República o el franquismo, en que la actitud de las minorías intelectuales y la del resto de la sociedad fueron divergentes.

De todos modos, descartado cualquier intento de definición esencialista por su misma intención metahistórica, la pregunta inevitable que plantea el último párrafo del libro es ver si al lenguaje democrático no se le endosa acaso esa misma carga. No cabe dudar - y así conviene desearlo- de que sus normas de funcionamiento impidan la reelaboración del discurso de las dos Españas. Pero, al mismo tiempo, no es menos cierto que apelar a su condición de nuevo relato tal vez se esté revelando ineficaz para resolver la crisis de identidad hoy planteada en España.

Por lo demás, estamos ante un análisis lúcido, que cuenta con una pluma extraordinariamente ágil para explicar de manera sencilla cuestiones teóricas difíciles de entender. Un ensayo que, por último, vuelve a poner sobre la mesa la utilidad - y los usos- de la ciencia histórica en un momento en que, paradójicamente, las humanidades en su conjunto viven bajo permanente amenaza de extinción ${ }^{14}$.

Jacini en 1866, en Le condizione Della cosa pubblica in Italia dopo il 1866; al cabo, "la España oficial y política" y "la España contribuyente y trabajadora" estaban en boca de los republicanos Nicolás Salmerón y Ruiz Zorrilla en 1876, exiliados a la sazón en París», cfr. ANDRÉs-GALLEGO, J., op. cit., citando a CACHO VIU, V., «La imagen de las dos Españas», en Revista de Occidente, 60, 1986, pp. 49-54.

14 Respecto al concepto de «uso público de la Historia», véase la obra editada por Carlos ForCadell Álvarez y Juan José Carreras Ares, Usos públicos de la Historia, Marcial Pons, Madrid, 2003. E igualmente, su complemento en las ponencias del VI Congreso de la Asociación de Historia Contemporánea dedicado a este mismo tema, con idéntico título, (Prensas Universitarias de Zaragoza, Zaragoza, 2003). 